\title{
Development and beam commissioning of a continuous-wave window-type radio-frequency quadrupole
}

\author{
P. P. Gan, K. Zhu, Q. Fu, H. P. Li, M. J. Easton, Q. Y. Tan, S. Liu, \\ S. L. Gao, Z. Wang, and Y. R. Lu \\ State Key Laboratory of Nuclear Physics and Technology, Peking University, Beijing 100871, China
}

W. P. Dou, Q. Wu, C. Wang, Y. He, and H. W. Zhao

Institute of Modern Physics, China Academy of Science, Lanzhou 730000, China

(Received 6 December 2018; published 7 March 2019)

\begin{abstract}
The radio-frequency quadrupole (RFQ) group at Peking University has built a window-type RFQ, operating at $162.5 \mathrm{MHz}$ in continuous-wave (cw) mode. It is designed to accelerate a $50 \mathrm{~mA}$ deuteron beam from $50 \mathrm{keV}$ to $1 \mathrm{MeV}$ with a vane length of $1.809 \mathrm{~m}$. The cavity was fabricated in two segments using $100 \%$ oxygen-free electronic (OFE) copper. Using an iterative assembly and measurement procedure for the precise alignment of the two segments, we reduced the assembly errors to within $\pm 0.05 \mathrm{~mm}$. The radio frequency (rf) measurements of the whole cavity show excellent rf properties, with the measured intrinsic Q-value of 8962 , which equates to $96 \%$ of the simulated value for OFE copper. We also investigated field fluctuations caused by misalignment between the two segments, and studied their impact on the beam transmission using beam dynamics simulations. During field tuning, we compiled a set of unique tuning rules for the window-type RFQ. After tuning, the maximal field unflatness of the single quadrant is within $\pm 2 \%$, and the asymmetry of the four quadrants is within $\pm 1 \%$. During rf conditioning, the cw power of the cavity reached $55 \mathrm{~kW}$ within 32 hours, and we have recorded nearly seven hours of stable running at a $\mathrm{cw}$ power of $50 \mathrm{~kW}$. The measured bremsstrahlung spectrum shows that the accelerator needs $49.9 \mathrm{~kW}$ to generate the intervane voltage of $60 \mathrm{kV}$, with a specific shunt impedance of $130.5 \mathrm{k} \Omega \mathrm{m}$. An $\mathrm{H}_{2}^{+}$ion beam extracted from an electron cyclotron resonance ion source was used for the beam commissioning, because deuteron beam acceleration will bring a serious radiation field. We achieved stable and robust acceleration of about $1.5 \mathrm{~mA} \mathrm{cw} \mathrm{H}_{2}^{+}$beam for one hour.
\end{abstract}

DOI: 10.1103/PhysRevAccelBeams.22.030102

\section{INTRODUCTION}

High-current continuous-wave (cw) RFQs are a research hot spot in the field of linear accelerators, as they can be applied to fusion material irradiation, accelerator driven subcritical systems, nuclear waste transmutation and nuclear fuel proliferation, radioactive nuclear beam production and compact high-intensity neutron source. In recent decades, several high-current cw RFQs have been built, such as the IFMIF RFQ [1], C-ADS injector-II RFQ [2], SARAF RFQ [3] and the LEDA RFQ [4]. Most of these RFQs are at the experimental stage, with no full cw power

\footnotetext{
*Corresponding author. zhukun@pku.edu.cn

Corresponding author. yrlu@pku.edu.cn
}

Published by the American Physical Society under the terms of the Creative Commons Attribution 4.0 International license. Further distribution of this work must maintain attribution to the author(s) and the published article's title, journal citation, and DOI. operation or with limited $\mathrm{cw}$ operation time. Therefore, the realization of a high-current cw RFQ is still a significant challenge. The most common problems for cw RFQs are [5]: sparking or multipacting at higher power; overheated spots at problem location such as the couplers, tuners, or contact fingers; detuning due to beam loading, rf heating and lost beam heating.

Since 2013, Peking University (PKU) and the Institute of Modern Physics (IMP) have been collaborating on a new "973" project, which aims to accumulate experience in design and fabrication of high-current cw RFQs and promote their development by building a $50-\mathrm{mA} \mathrm{cw}$ deuteron RFQ. The problems for cw RFQs mentioned above provide a lot of valuable lessons for our RFQ design. We have already completed the beam dynamics design and the rf structure design [6,7]. The main parameters of this RFQ are listed in Table I. We optimized the beam dynamics design to control the limiting current from the gentle bunching section to the end of the acceleration section, and adopted a matched and equipartitioned design method to reduce the radius of the transverse envelope, suppress the 
TABLE I. Main parameters of the window-type RFQ.

\begin{tabular}{lc}
\hline \hline Parameter & Value \\
\hline Operating frequency [MHz] & 162.5 \\
Particle & $\mathrm{D}^{+}$ \\
Beam current [mA] & 50 \\
Duty factor & $100 \%$ \\
Input/output energy [MeV] & $0.05 / 1.03$ \\
Intervane voltage [kV] & 60 \\
Length of the vanes [m] & 1.809 \\
Cavity radius [mm] & 170.00 \\
Intrinsic quality factor (simulated) & 9300 \\
Power (simulated) [kW] & 48.9 \\
Kilpatrick coefficient & 1.67 \\
Pole tip radius [mm] & $2.57-3.32$ \\
Average aperture [mm] & 3.88 \\
Mode separation between & 2.99 \\
$\quad$ TE $E_{210}$ and TE ${ }_{110}($ simulated) $[\mathrm{MHz}]$ & \\
\hline \hline
\end{tabular}

increase of the emittance, and reduce the beam loss at highenergy section. The RFQ copper cavity is shown in Fig. 1. It adopts a window-type structure which is more compact than the traditional four-vane structure. We achieved low power consumption and sufficient mode separation with this design.

Several window-type RFQs have completed if or beam commissioning, such as the TWAC RFQ [8], ATLAS RFQ [9,10] and the RFQ for NICA [11]. They operate at lower frequencies and are designed to accelerate heavy ions. So far, only the ATLAS RFQ has realized cw running. Our RFQ will be the first high-frequency windowtype cw RFQ.

In this paper, Sec. II presents the fabrication, rf measurement and tuning results of the window-type cavity; Sec. III describes the setup of the two couplers and high power test of the cavity; Sec. IV demonstrates the beam commissioning results, and the comparison with other $\mathrm{cw}$ deuteron RFQs is given in Sec. V.

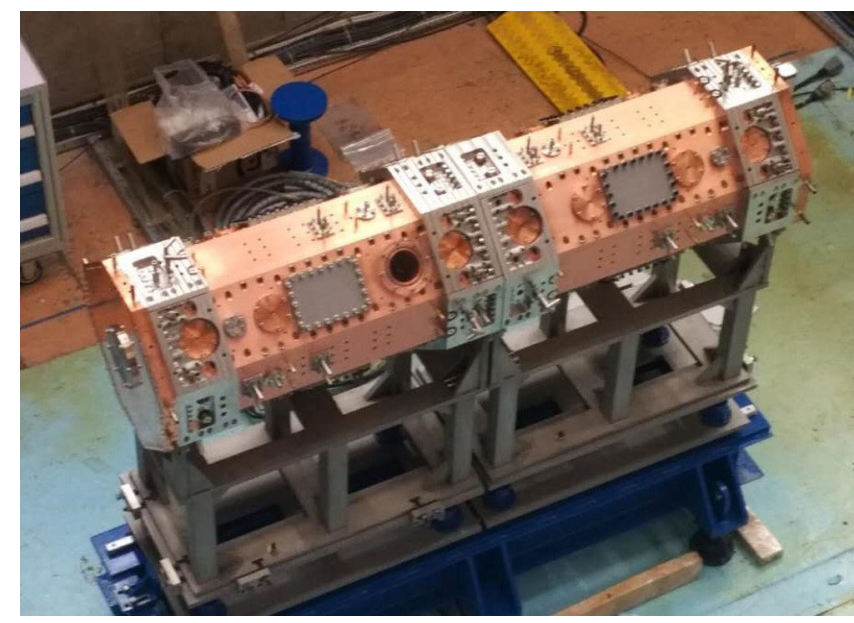

FIG. 1. View of the whole window-type RFQ cavity.

\section{FABRICATION AND LOW POWER EXPERIMENT}

\section{A. Fabrication and measurement}

For high-current cw RFQ accelerators, the successful transmission and acceleration of the beam is highly influenced by the accuracy of the machining and assembly process. Our design parameters require a precision better than $0.05 \mathrm{~mm}$.

As can be seen in Fig. 1, the RFQ cavity consists of two almost identical segments and end plates, which are all made of oxygen-free copper. Each segment is $904.50 \mathrm{~mm}$ long, and is divided into four vanes and four cavity walls for manufacturing. The RFQ is equipped with 28 tuners, with a diameter of $60 \mathrm{~mm}$, as well as two couplers, eight vacuum ports, eight pickups and 56 cooling connectors. The reason why we need so many tuners is that because of the design of varying pole tip radius, the original electric field along the RFQ is relatively rough, and 16 tuners with 50-mm diameter are not enough for field tuning as discussed in Ref. [7]. The fabrication procedure includes the following main stages: (i) preliminary machining of vanes, cavity walls and end plates; and drilling of watercooling channels; (ii) semifinishing and fine machining; (iii) hydrostatic pressure testing of the cooling channels; (iv) assembly of each segment, frequency check of individual segments; followed by disassembly of segments and cleaning of all parts; (v) assembly and final brazing; (vi) postbrazing machining, rf measurement, final cleaning and vacuum leak checking of each segments; (vii) assembly of the segments and end plates, and installation of external water-cooling pipes and vacuum system components.

In order to ensure the high precision, we performed coordinate measuring machine (CMM) measurements of all components at various stages of the manufacturing process. We used ball-end milling tools to process the vane modulations, as the RFQ was designed with variable

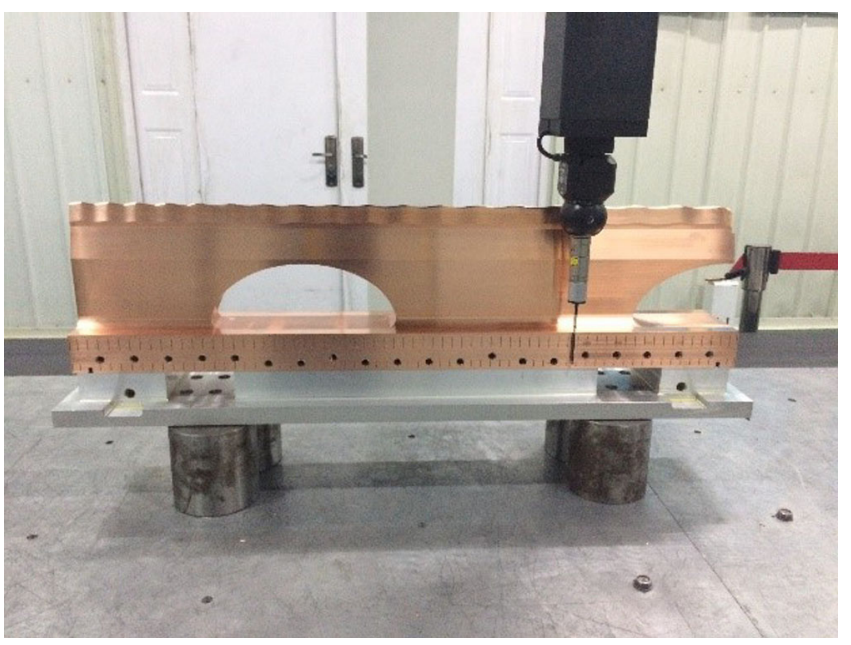

FIG. 2. Machining error measurement of the electrodes. 
TABLE II. Maximum machining errors of the electrodes (unit: $\mathrm{mm}$ ).

\begin{tabular}{lcc}
\hline \hline Electrodes & Segment No. 1 & Segment No. 2 \\
\hline Vertical electrode I & 0.030 & 0.019 \\
Vertical electrode II & 0.031 & 0.034 \\
Horizontal electrode I & 0.024 & 0.027 \\
Horizontal electrode II & 0.027 & 0.032 \\
\hline \hline
\end{tabular}

transverse radius of the vane tips. Figure 2 shows the machining error measurement of the electrodes. The results are listed in Table II. The maximum machining error is $0.034 \mathrm{~mm}$, located at the vane tip.

We assembled the RFQ components vertically, as shown in Fig. 3. During the test of each segment, we adopted a method combining CMM measurement and electric field distribution measurement to ensure high-accuracy assembling. The measured electric field distribution of the four quadrants can directly reflect the symmetry of the cavity. We measured the field distribution once we assembled one segment, and then performed the next adjustment based on the measurement results. This process is repeated until the field distribution and the CMM measurement meet our requirements. After properly adjusting the vanes, we measured the transverse assembling errors to be within $\pm 0.05 \mathrm{~mm}$ at both ends of each segment. The two segments were brazed and postprocessed successively. Their vacuum levels reached $1 \times 10^{-5} \mathrm{~Pa}$. Next, we used a laser tracking system to align the two segments. The transverse alignment error was $-0.03 \mathrm{~mm}$. Finally, we achieved a machining precision and an assembly precision better than $0.05 \mathrm{~mm}$, well within the targets set for this RFQ.

\section{B. rf measurement and tuning}

After the segments were joined together, we measured the rf characteristics of the whole RFQ cavity using two pickups in transmission mode with very weak coupling. As shown in Table III, the measured results are close to those predicted by CST [12] simulations. The operating frequency of the whole RFQ without tuning and powerinput loops is $0.233 \mathrm{MHz}$ below the simulated value. The measured $\mathrm{Q}_{0}$ of the operating mode is $96 \%$ of the simulated value.

Figure 4 shows the 20-mm off-axis electric field distributions of the four quadrants after primary collimating. There is a clear step in the middle of the cavity, at the location of the electrode seams between the two segments, as shown in Fig. 5. This electric field step is caused by the assembling error of the two segments-especially the transverse alignment error.

As this electric field step may affect the beam transmission, it is necessary to study it through beam dynamics simulations. However, from the distribution of the electric field, we cannot determine the nature of the alignment error. To simplify the simulations, we studied the transmission efficiency and acceleration efficiency under two separate error conditions: a translation at 45 degrees to the vane direction, and a rotating shift of the second segment. The acceleration efficiency is a parameter to describe how many particles are accelerated to the designed energy. The simulation results, obtained using TOUTATIS [13], are shown in Fig. 6. As it is difficult to characterize the rotation of electrodes in TOUTATIS, we use the way that the electrode is shifted in Fig. 6(b) to represent rotation, using two translation effects. The first type of translation results in a deviation of the central axis of the second cavity, and as the shift value increases, the transmission efficiency reduces with a relatively slow speed. The second rotation shift does not cause a change in the central axis, but maintains the symmetry of the four electrodes. Only when the shift exceeds $0.20 \mathrm{~mm}$, the transmission efficiency begins to decrease significantly. Therefore, the effect of our transverse alignment error on the transmission efficiency of the beam is not more than $1 \%$.

Tuning of the RFQ includes adjusting the cavity frequency and the electric field distribution. Figure 7 illustrates the positions of the tuners relative to the coupling windows and the magnetic field distribution. Figure 8 shows the effect on the cavity frequency of inserting tuners

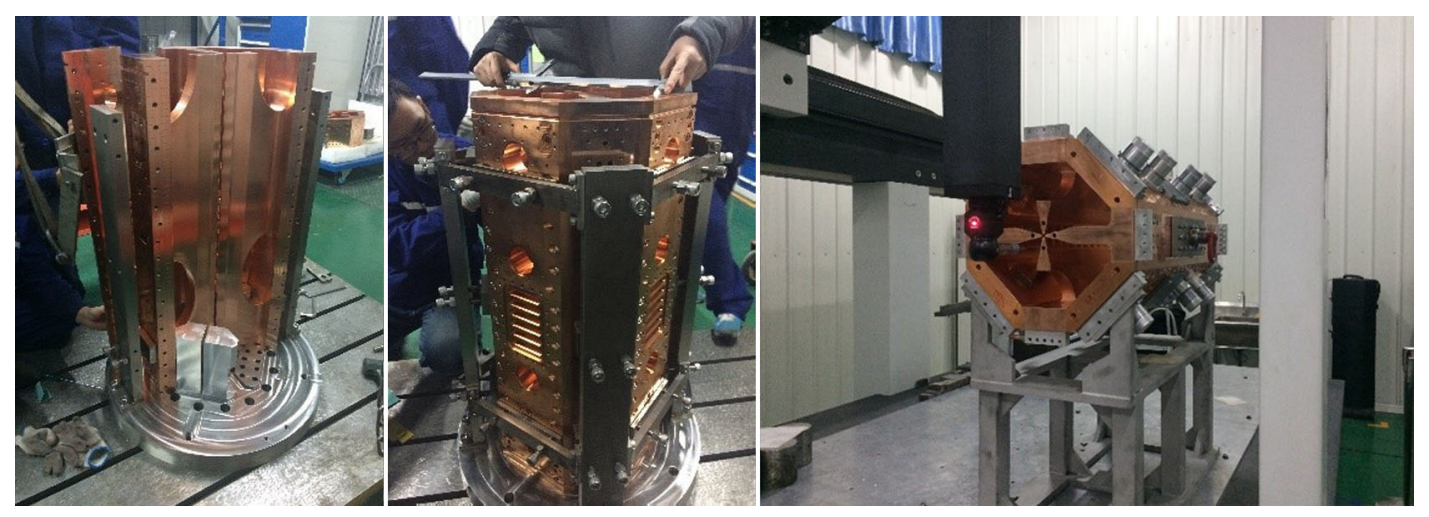

FIG. 3. Single cavity assembly process and assembling error measurement. 
TABLE III. Comparison of the simulated and measured rf parameters of the cavity.

\begin{tabular}{|c|c|c|c|c|c|c|c|c|}
\hline \multirow[b]{2}{*}{ Mode } & \multicolumn{4}{|c|}{ Simulated } & \multicolumn{4}{|c|}{ Measured } \\
\hline & $\begin{array}{c}\text { Frequency } \\
{[\mathrm{MHz}]}\end{array}$ & $\begin{array}{l}\text { Intrinsic } \\
\text { quality } \\
\text { factor }^{\mathrm{a}}\end{array}$ & $\begin{array}{c}\text { Frequency } \\
{[\mathrm{MHz}]}\end{array}$ & $\begin{array}{l}\text { Intrinsic } \\
\text { quality } \\
\text { factor }^{\mathrm{a}}\end{array}$ & $\begin{array}{l}\text { Loaded } \\
\text { quality } \\
\text { factor }^{\mathrm{a}}\end{array}$ & $S_{21}[\mathrm{~dB}]$ & $S_{11}[\mathrm{~dB}]$ & $S_{22}[\mathrm{~dB}]$ \\
\hline $\mathrm{TE}_{210}$ & 161.930 & 9300 & 161.697 & 8962 & 7952 & -18.68 & -1.32 & -0.89 \\
\hline${ }^{0} \mathrm{TE}_{110}$ & 164.922 & 10427 & 164.664 & 10022 & 8654 & -16.80 & -1.51 & -1.24 \\
\hline $\mathrm{TE}_{211}$ & 177.840 & 5933 & 177.200 & 5916 & 5764 & -31.84 & -0.30 & -0.15 \\
\hline${ }^{\pi} \mathrm{TE}_{110}$ & 180.548 & 4298 & 182.645 & 4241 & 3896 & -21.40 & -0.85 & -0.69 \\
\hline${ }^{0} \mathrm{TE}_{111}$ & 183.273 & 4667 & 185.447 & 3349 & 3138 & -23.73 & -0.67 & -0.50 \\
\hline
\end{tabular}

${ }^{\text {a }}$ The electric conductivity of copper is adopted as $\sigma=5.0 \times 10^{7} \mathrm{~S} / \mathrm{m}$.

1-7 of the first quadrant to different depths in turn, and the change of the cavity frequency can be measured, as shown in Fig. 8. The seven curves are almost resolved into three curves, demonstrating that the tuning capabilities fall into three distinct tuning rates $(1.48,2.38$, and $2.88 \mathrm{kHz} / \mathrm{mm})$.

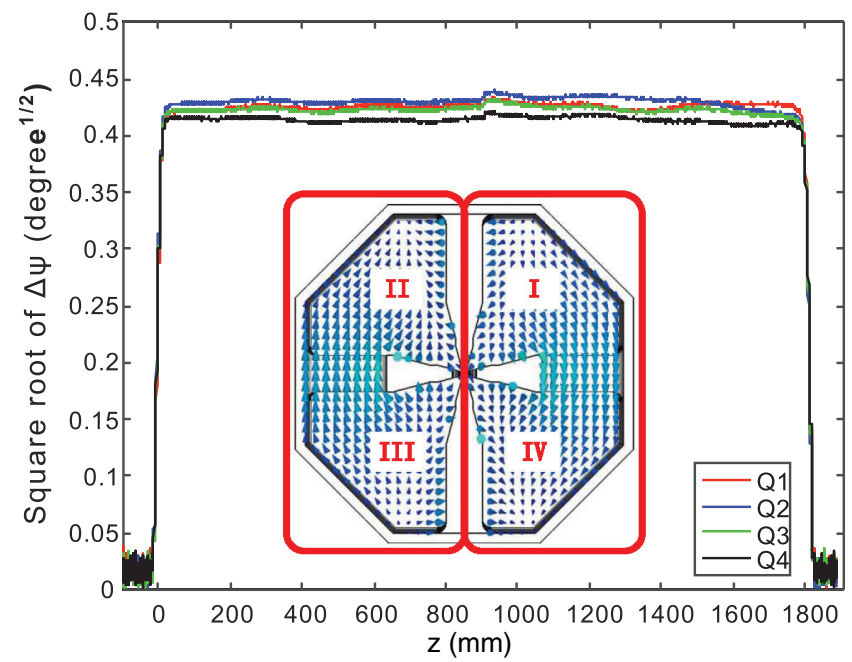

FIG. 4. Electric field distributions of the four quadrants after primary collimating.

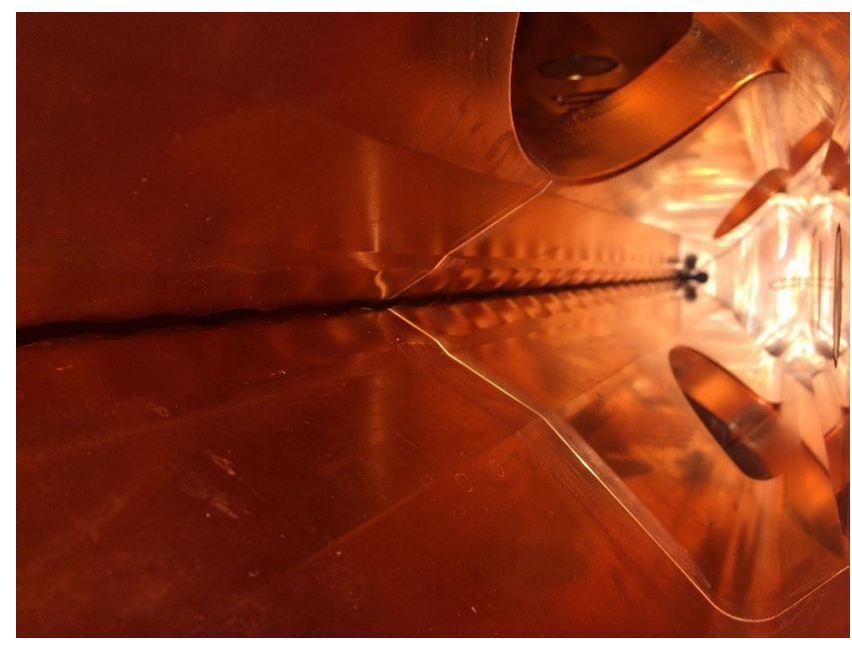

FIG. 5. View of the electrode seams between the two segments.
This is because the magnetic field varies periodically with the coupling windows and the tuners in different longitudinal positions correspond to different magnetic field values (see Fig. 7).

Through simulation, we obtained the effect of the tuner at different positions on the four-quadrant electric field. Figure 9 shows the effect of 60 -mm insertion of tuner 1 and

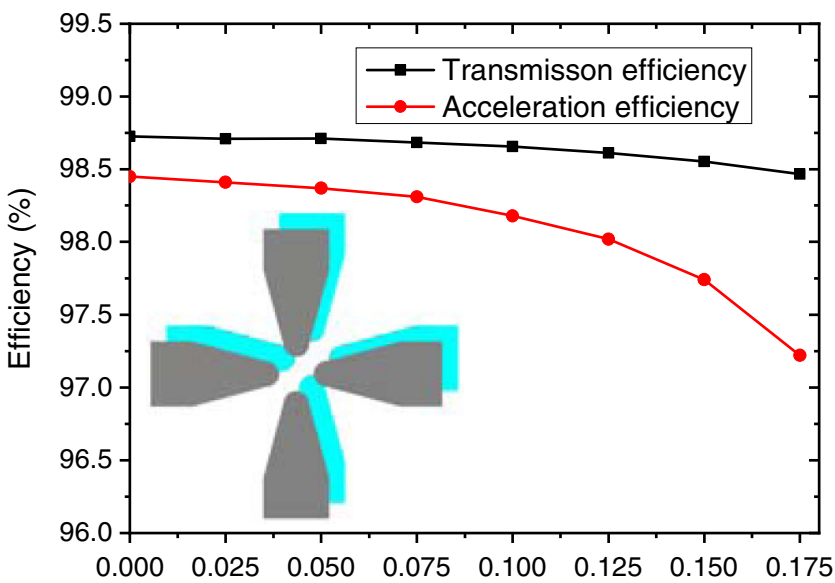

(a) Shift value $(\mathrm{mm})$

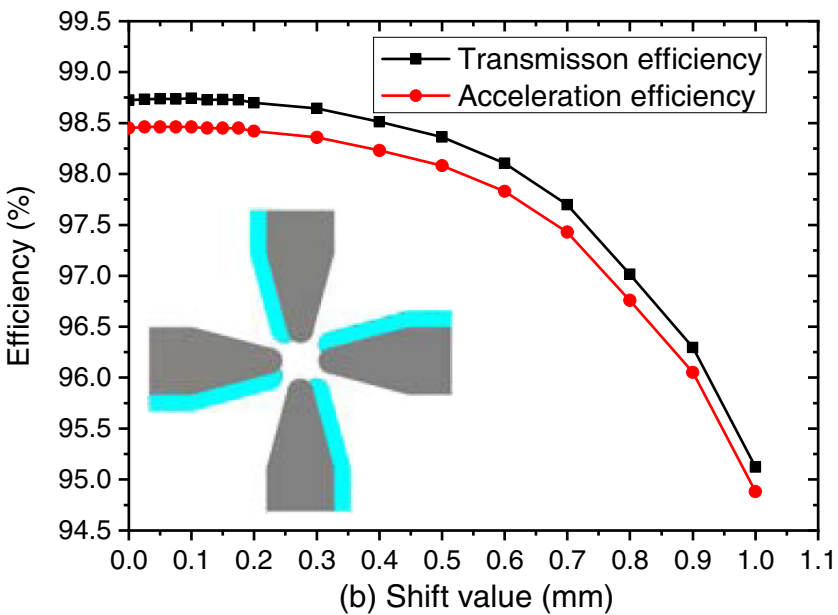

FIG. 6. Simulated transmission and acceleration efficiency under the effect of alignment errors of the second cavity: (a) 45-degree shift and (b) rotating shift. 

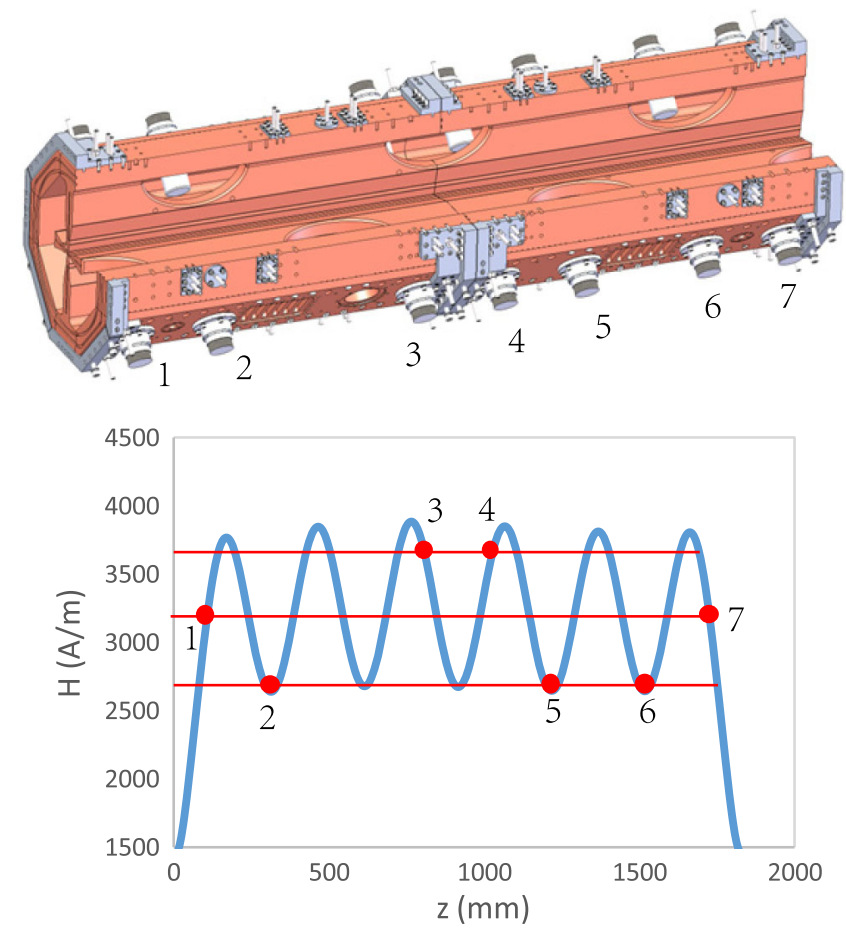

FIG. 7. Positions of tuners relative to (top) the coupling windows and (bottom) the magnetic field distribution.

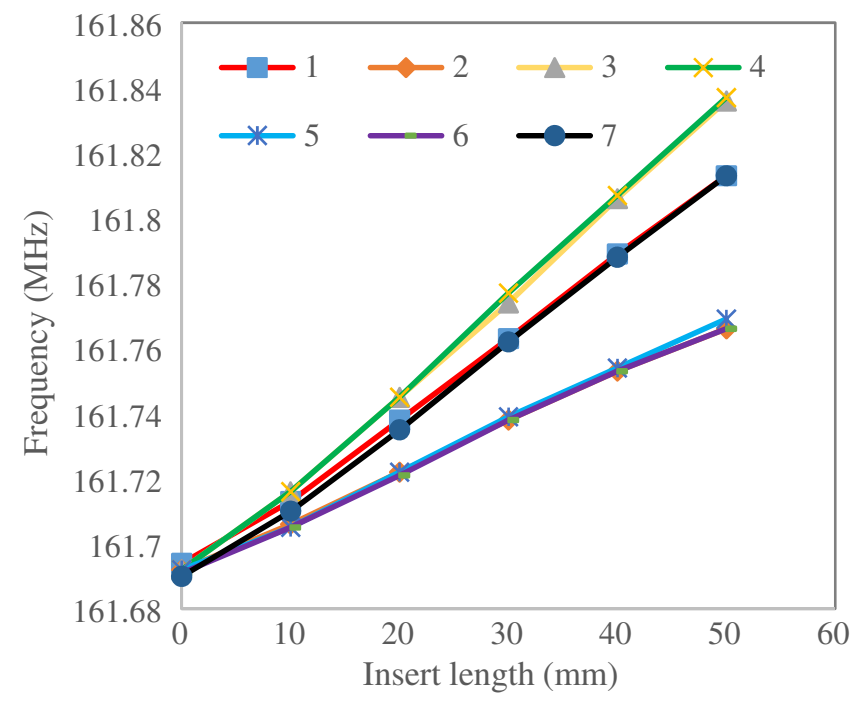

FIG. 8. Cavity frequency as a function of the inserted length of each tuner in quadrant I.

tuner 3 in the first quadrant on the electric field distribution of the four quadrants. Because of the half-window structure at the end of the horizontal electrodes, quadrants I and IV, and quadrants II and III are strongly coupled together, respectively. On the other hand, because of the windows in the vertical electrodes, quadrants I and II, and quadrants III and IV are weakly coupled together, respectively. Adjusting tuner 1, because the end coupling effect is strong, the electric field of the mutually strongly
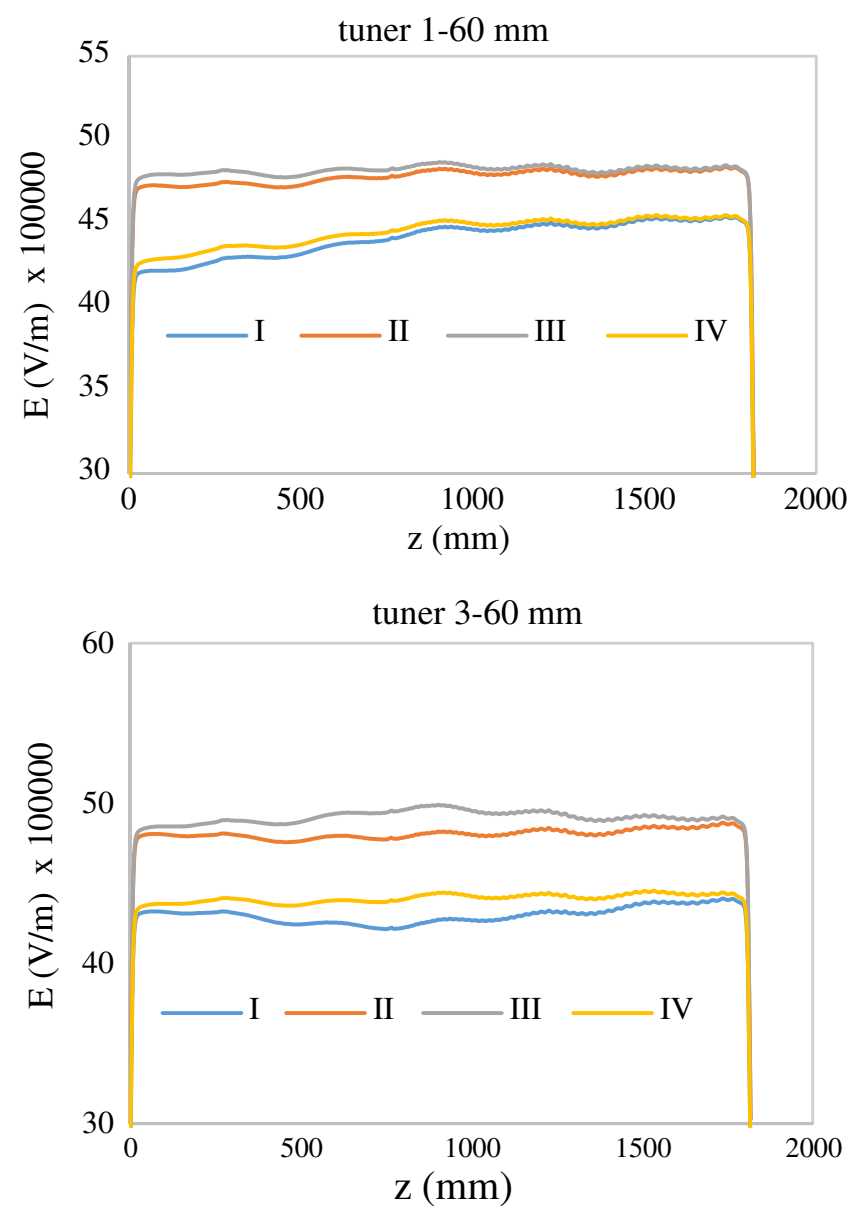

FIG. 9. Effect of $60 \mathrm{~mm}$ insertion of tuner 1 and tuner 3 in the first quadrant on the electric field distribution of the four quadrants (under $1 \mathrm{~J}$ stored energy).

coupled quadrants moves almost together. While adjusting tuner 3 , the coupling effect of the strongly coupled quadrants is not so obvious. Thereby, to tune the asymmetry between the strongly coupled quadrants, tuners 3 and 4 are the most effective.

We carried out the tuning of the entire cavity based on the above considerations. In terms of electric field tuning, the aim of tuning is to adjust the unflatness of the field in each quadrant and the asymmetry of the four quadrants to within $\pm 1 \%$; in terms of frequency tuning, as the cavity frequency will be reduced due to the thermal expansion of the cavity under high power conditions, we calculated that the cavity frequency should be tuned to $162.75 \mathrm{MHz}$.

The unflatness of the field and the asymmetry of four quadrants were calculated according to the following two formulas, respectively:

$$
\begin{gathered}
\text { Unflatness }=\frac{E_{Q k}-\overline{E_{Q}}}{\overline{E_{Q}}} \times 100 \%, \\
\text { Asymmetry }=\frac{E_{Q k}-\overline{E_{k}}}{\overline{E_{k}}} \times 100 \% .
\end{gathered}
$$


Here the subscript $Q(Q=I, I I, I I I, I V)$ is the quadrant label, and the $k(k=1,2,3, \ldots)$ is the point number that refers to different longitudinal position along the cold model. Thus, $\overline{E_{Q}}$ is the average electric field of a quadrant, and $\overline{E_{k}}$ is the average of four quadrants' field at a longitudinal position.

Before tuning, as shown in Fig. 10, the maximum unflatness of the field in each quadrant ranges from $+3.04 \%$ to $-2.61 \%$, and the asymmetry of the four quadrants ranges from $+2.95 \%$ to $-2.61 \%$. It indicates that the initial state is good and the target mentioned before can be achieved without too many adjustments. During the tuning process, tuners 3 and tuner 4 play an important role in adjusting the asymmetry between the strongly coupled quadrants, which confirms the tuning rules we obtained from the simulations.

After tuning, we measured the frequency as 162.745 MHz, and the $\mathrm{Q}_{0}$ value as 8019 (tuner and end
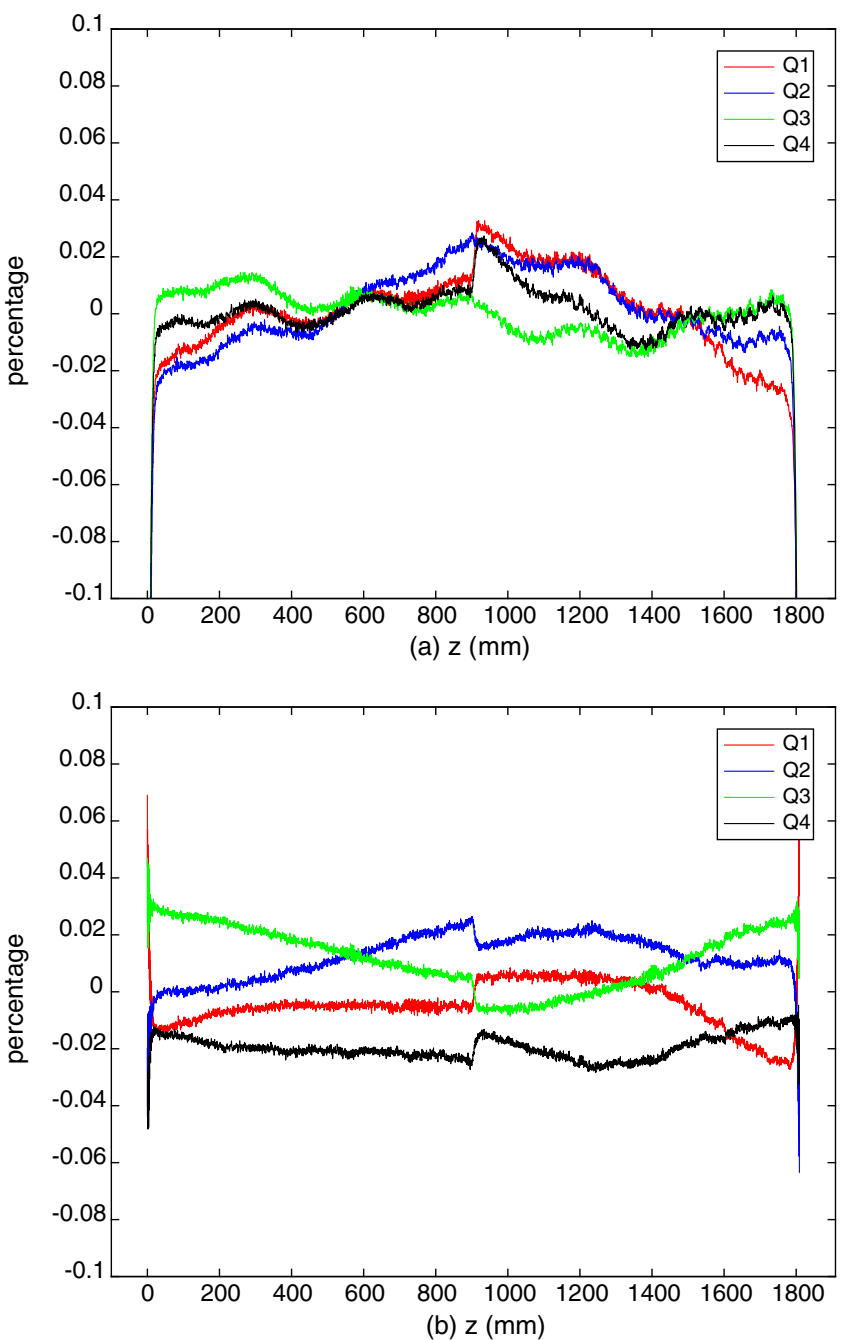

FIG. 10. (a) The unflatness of the field in each quadrant and (b) the asymmetry of the four quadrants at frequency of 161.688 MHz before tuning.
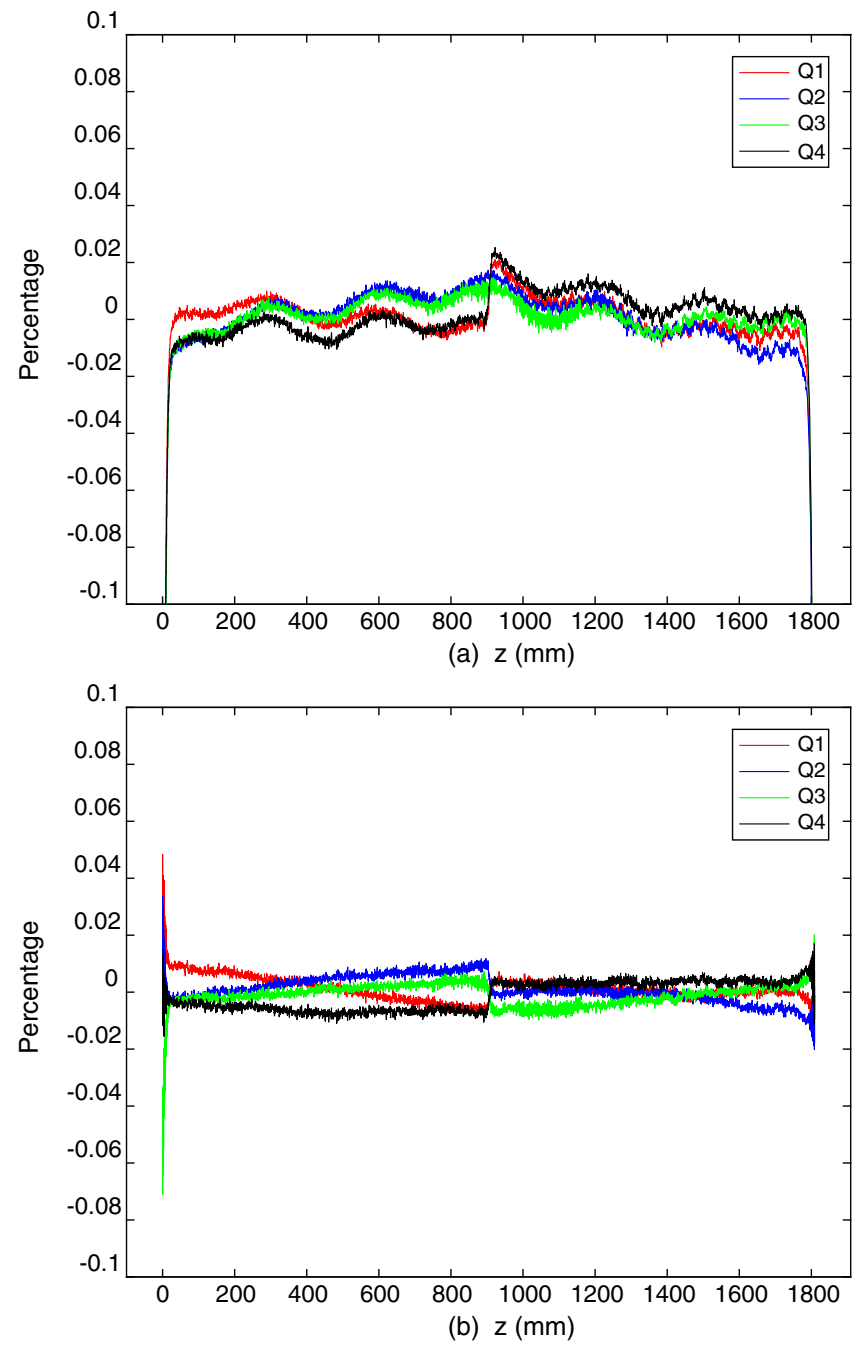

FIG. 11. (a) The unflatness of the field in each quadrant and (b) the asymmetry of the four quadrants at frequency of 162.745 MHz after tuning.

plate are aluminum). As shown in Fig. 11, excluding the electric field step discussed above, the maximum unflatness of the field in each quadrant ranges from $+1.53 \%$ to $-1.28 \%$, and the asymmetry of the four quadrants ranges from $+0.91 \%$ to $-0.77 \%$. Furthermore, the electric field distribution of the four quadrants is very similar to the simulated field distribution, including the fluctuations caused by the magnetic coupling windows and the modulations of the acceleration section, as shown in Fig. 12.

\section{III. rf CONDITIONING}

\section{A. Coupler setup}

The RFQ uses two couplers for rf input. Before rf conditioning, we needed to set the coupling factor to the target value by rotating the couplers. In order to leave enough margin for adjustments, the loop area of the coupler is $725.6 \mathrm{~mm}^{2}$, larger than the simulated required value of 


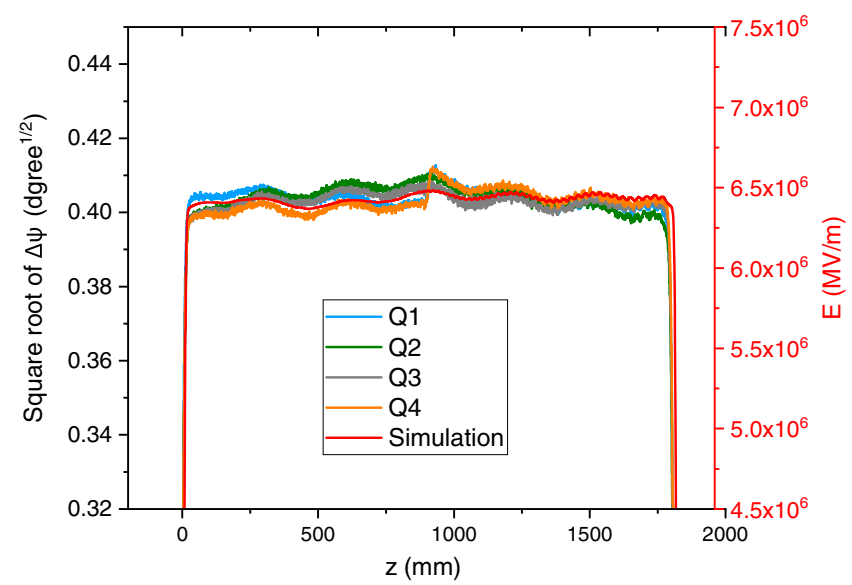

FIG. 12. Comparison of measured and simulated electric field distributions after tuning.

$575 \mathrm{~mm}^{2}$. We were told that the maximum beam current that can be extracted from the ion source is $20 \mathrm{~mA}$. This means that the total coupling factor needed to be set as 1.4, that is, each coupler should be 0.7 . It should be noted that for a two-port network, the measured coupling factor is not the true value. This is because that looking from one coupler port, the other coupler port is equivalent to connect a load resistance of $50 \Omega$. The intrinsic quality factor $\mathrm{Q}_{0}$ becomes loaded quality factor $\mathrm{Q}_{L}$. According to the definition of the coupling factor, the measured coupling factors of a two-port network are given by

$$
\begin{aligned}
& \beta_{1}^{*}=\frac{Q_{L 2}}{Q_{e x 1}}=\frac{1}{\frac{1}{Q_{0}}+\frac{1}{Q_{e x 2}}} \cdot \frac{1}{Q_{e x 1}}=\frac{\beta_{1}}{1+\beta_{2}} \\
& \beta_{2}^{*}=\frac{Q_{L 1}}{Q_{e x 2}}=\frac{1}{\frac{1}{Q_{0}}+\frac{1}{Q_{e x 1}}} \cdot \frac{1}{Q_{e x 2}}=\frac{\beta_{2}}{1+\beta_{1}},
\end{aligned}
$$

where $\beta_{i}$ and $\beta_{i}^{*}$ are the true and measured coupling factor of the $\mathrm{i}$ port.

Therefore, the true coupling factors can be derived by [14]

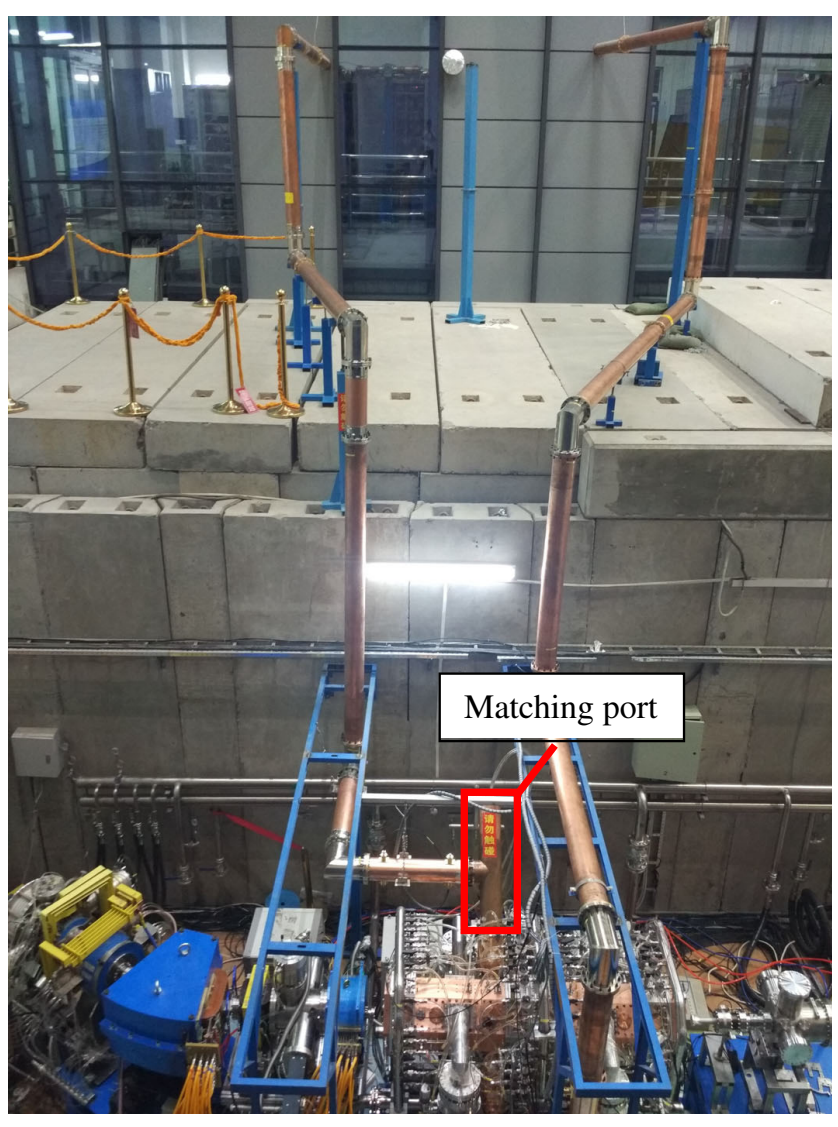

FIG. 13. The power feed system.

$$
\beta_{1}=\frac{\beta_{1}^{*}\left(1+\beta_{2}^{*}\right)}{1-\beta_{1}^{*} \beta_{2}^{*}}, \quad \beta_{2}=\frac{\beta_{2}^{*}\left(1+\beta_{1}^{*}\right)}{1-\beta_{1}^{*} \beta_{2}^{*}}
$$

We measured the coupling factor with and without matching ports included. The measurement results are listed in Table IV. Without matching ports, the frequency of the cavity was $162.732 \mathrm{MHz}$, and the $\mathrm{Q}_{0}$ value was 8643 . This is significantly larger than reported in Sec. II B above, because the end plates and tuners were now replaced with copper versions. The matching port (see Fig. 13) is a quarter wave of EIA $61 / 8$ " coaxial waveguide, with its own resonance frequency. If there is a mismatch with the

\begin{tabular}{|c|c|c|c|c|}
\hline \multirow[b]{2}{*}{ Two ports } & \multicolumn{2}{|c|}{ Without matching ports } & \multicolumn{2}{|c|}{ With matching ports } \\
\hline & Coupler I (in) & Coupler II (out) & Coupler I (in) & Coupler II (out) \\
\hline$S_{11}$ or $S_{22}[\mathrm{~dB}]$ & -7.52 & -7.55 & -7.28 & -7.24 \\
\hline Measured coupling factor & 0.407 & 0.409 & 0.396 & 0.394 \\
\hline Real coupling factor & 0.690 & 0.691 & 0.655 & 0.652 \\
\hline Loaded quality factor $\mathrm{Q}_{L}$ & \multicolumn{2}{|c|}{3630} & \multicolumn{2}{|c|}{3716} \\
\hline Intrinsic quality factor $\mathrm{Q}_{0}$ & \multicolumn{2}{|c|}{8643} & \multicolumn{2}{|c|}{8571} \\
\hline Frequency [MHz] & \multicolumn{2}{|c|}{162.732} & \multicolumn{2}{|c|}{162.833} \\
\hline
\end{tabular}
RFQ cavity, it will have an impact on the measured results.

TABLE IV. Measurement results for the two couplers. 
As can be seen from Table IV, the frequency shifts to 162.833 MHz after the matching ports are connected to the couplers.

\section{B. High power test}

The RFQ is driven by two solid-state rf amplifiers of $80 \mathrm{~kW}$ through two couplers, as shown in Fig. 13. We developed a control system to monitor the RFQ operation, including two vacuum gauges, two pickup loops, two arc detectors and 30 sets of thermometers and flow meters. The rf conditioning started at the cavity vacuum level of $1.9 \times 10^{-6} \mathrm{~Pa}$ and was performed in $\mathrm{cw}$ mode.

After about 32 hours of effective conditioning, cw power up to $55 \mathrm{~kW}$ was transmitted into the RFQ. During the conditioning, the only problems triggered were occasional vacuum and power reflection protection trips, and no sparks were detected by the arc detectors. The RFQ had operated for 1 hour and 25 minutes in $55 \mathrm{~kW}$ cw mode before a spark occurred. Additionally, we recorded over seven hours of uninterrupted (no-spark) operations at $\mathrm{cw}$ power of $50 \mathrm{~kW}$, as shown in Fig. 14. These results indicate that the RFQ cavity design was successful and it can run stably in high power $\mathrm{cw}$ mode.

Figure 15 shows the change of frequency with cavity power. It can be seen that the frequency decreases almost linearly with the cavity power, with a slope of $2.8 \mathrm{kHz} / \mathrm{kW}$.

\section{Intervane voltage measurement}

We carried out the intervane voltage calibration using $\mathrm{x}$-ray spectrum measurements. The high voltage between the intervanes leads to field emission, and these emitted electrons are accelerated to the energy corresponding to RFQ voltage and bombard the copper vanes, resulting in Bremsstrahlung $x$-ray emission, the maximum energy of these $\mathrm{x}$ rays corresponds to the vane voltage. We used a $\mathrm{CdTe}$ spectrometer for the measurements of $\mathrm{x}$-ray spectra.

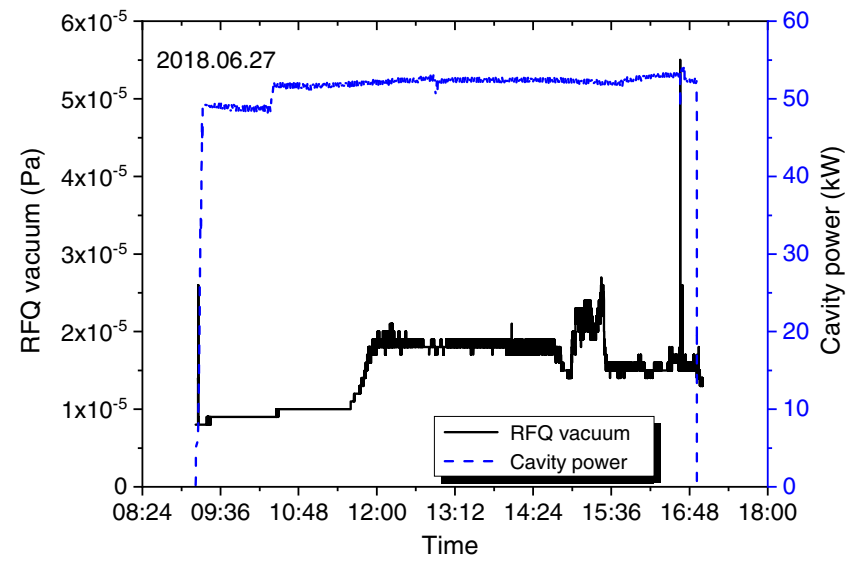

FIG. 14. Uninterrupted (no-spark) operations at $\mathrm{cw}$ power of $50 \mathrm{~kW}$ recorded over 7 hours.

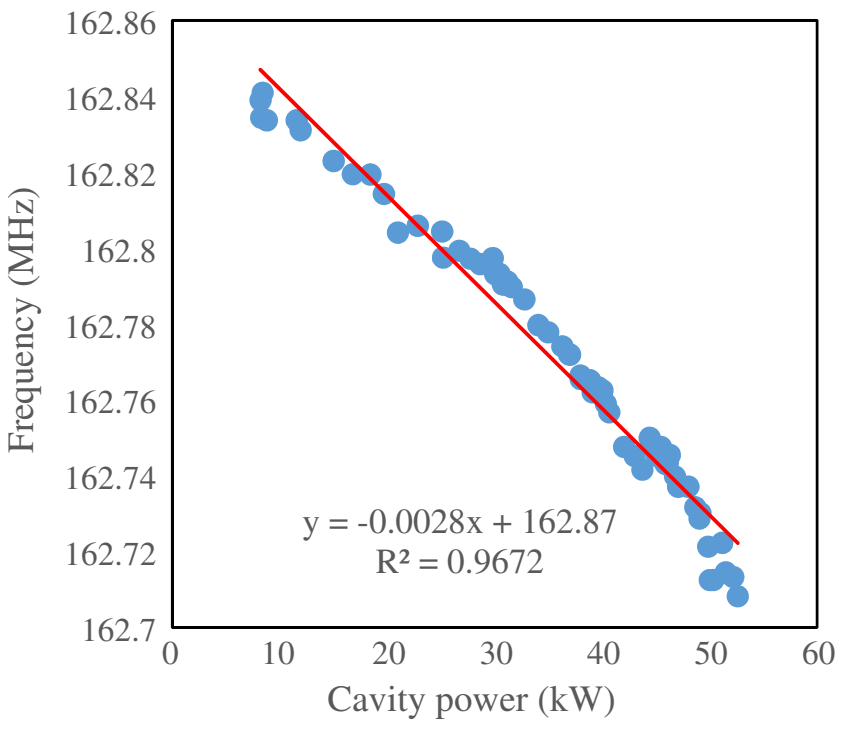

FIG. 15. Frequency of the RFQ as a function of cavity power.

It was calibrated with ion-55 and amercium-241 sources, as shown in Fig. 16.

We added a special quartz window to the RFQ to allow the $\mathrm{x}$ rays to reach the spectrometer. The spectrometer was mounted directly facing the intervane gap, as shown in Fig. 17. In order to attenuate the high intensity of the $x$ rays, we covered the quartz window with a 3-mm-thick circular copper plate.

Figure 18 shows a typical $\mathrm{x}$-ray spectrum corresponding to the RFQ voltage. There are different methods to quantify the cutoff energy of the $x$ rays [15-17]. As our measured spectra are smooth and clean, we used linear fitting with a beveled edge for the high energy region, and took the horizontal intercept as the cutoff energy. We measured the intervane voltage under different cavity power conditions, at three separate times. Figure 19 shows the results. The specific shunt impedance of the RFQ can be deduced from the slope of the linear fitting line. The average value of the three measurements of the specific shunt impedance is $130.5 \mathrm{k} \Omega \mathrm{m}$, which is $93 \%$ of our simulated value.

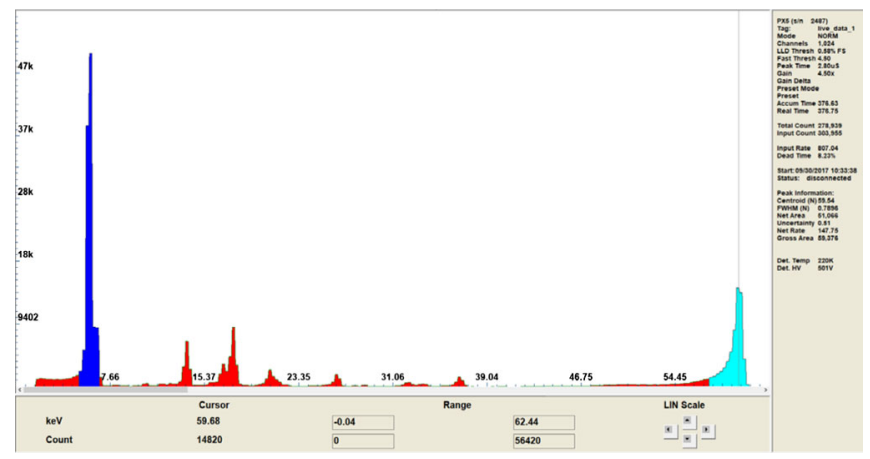

FIG. 16. Spectrometer calibration with ion-55 and amercium241 sources. 


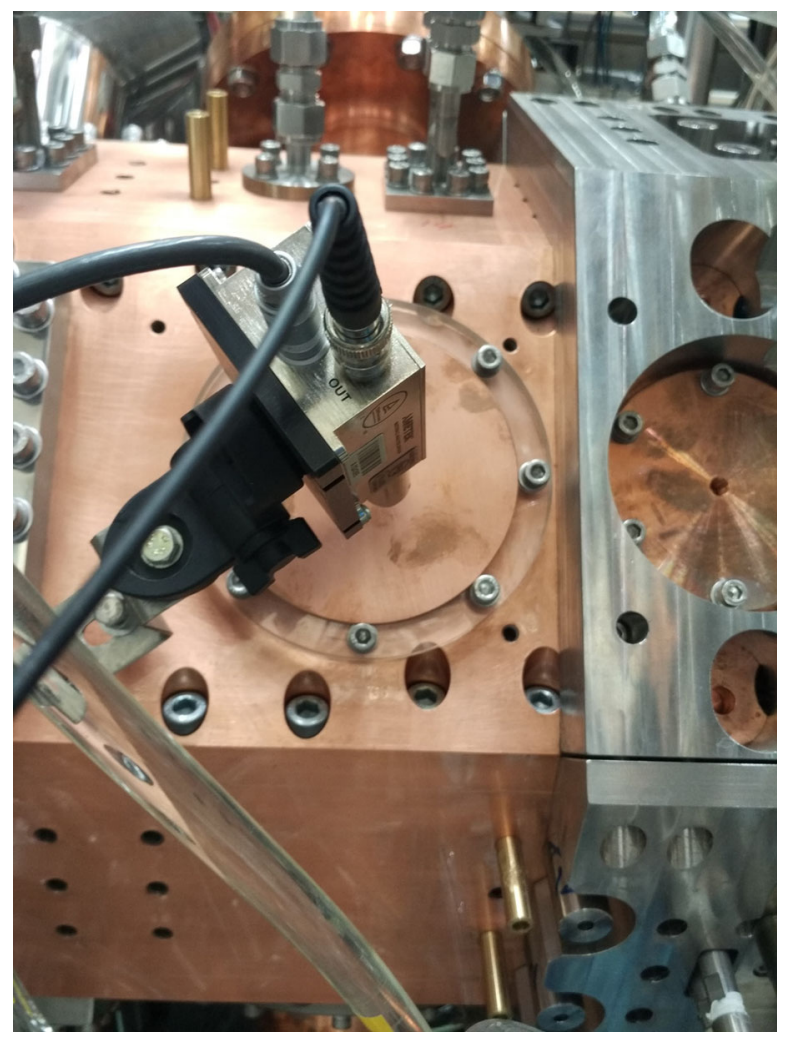

FIG. 17. Location of the quartz window and spectrometer.

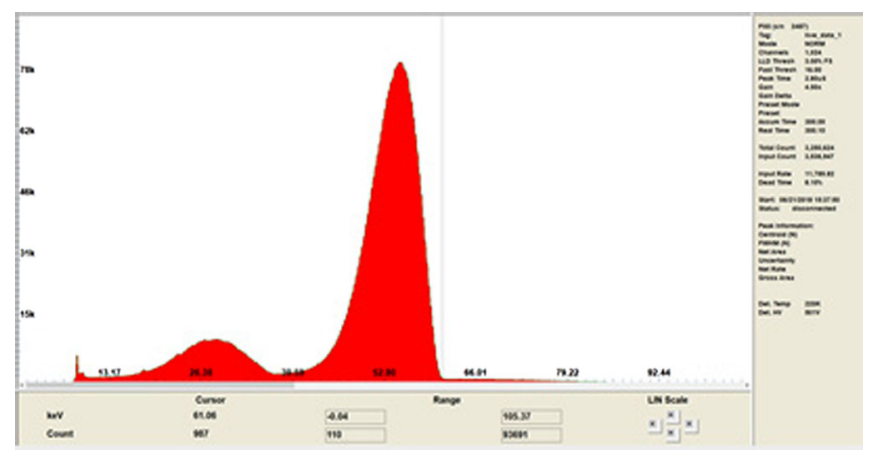

FIG. 18. X-ray spectrum corresponding to the $61 \mathrm{kV}$ intervane voltage.

Calculated from the measured specific shunt impedance, an intervane voltage of $60 \mathrm{kV}$ corresponds to a cavity power of $49.9 \mathrm{~kW}$, which is very close to the simulated value of $48.9 \mathrm{~kW}$.

\section{BEAM COMMISSIONING}

The experimental setup for beam commissioning of the RFQ is shown in Fig. 20. It consists of an electron cyclotron resonance (ECR) ion source, a low energy beam transport (LEBT) system based on three solenoids and a $32.5^{\circ}$ bending magnet, the RFQ and a medium energy beam transport (MEBT) section. Between the Solenoid 3 and the

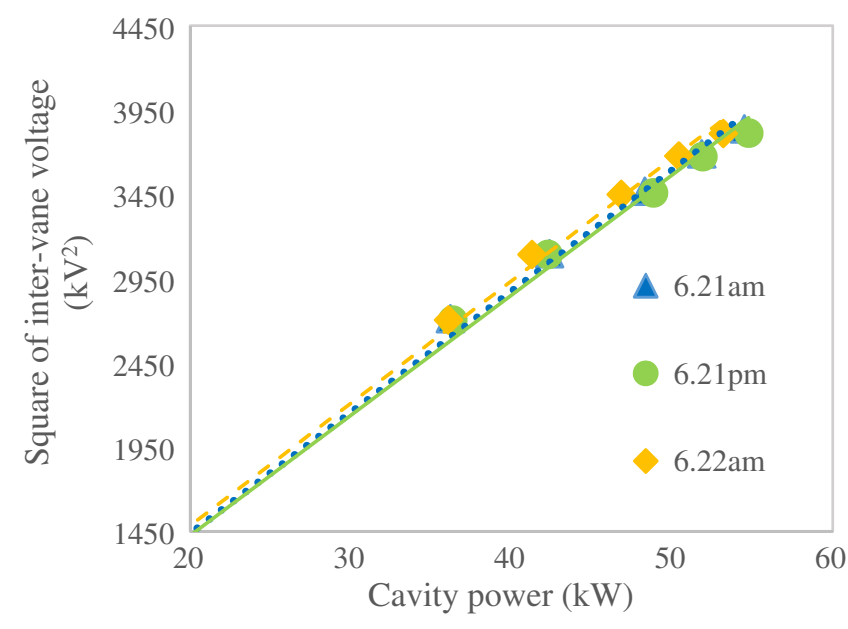

FIG. 19. Square of intervane voltage as a function of cavity power.

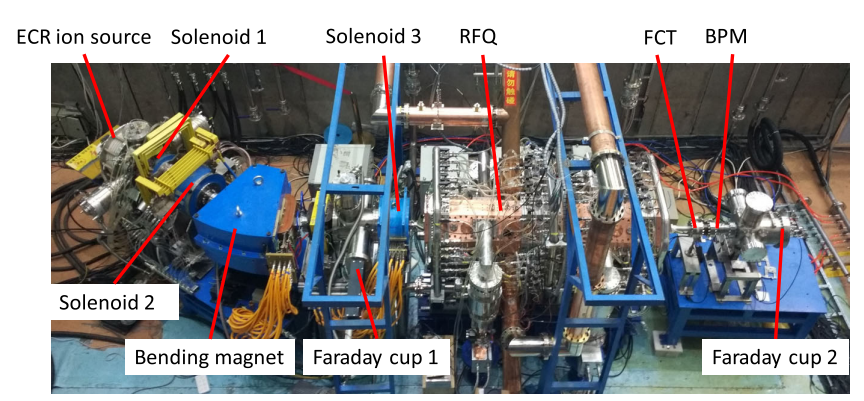

FIG. 20. Overview of the RFQ test area.

RFQ, there is a chopper used to provide pulsed beam for beam commissioning. Two water-cooled Faraday cups (FCs) were used for transmission measurement. The bias voltage of FC1 and FC2 were set to -300 and $-800 \mathrm{~V}$, respectively, to suppress secondary electron yield (SEY). A fast current transformer (FCT) and a beam position monitor (BPM) were installed after the exit of the RFQ for beam energy measurement. The extraction voltage of the ion source was fixed at $50 \mathrm{kV}$ to provide the design injection energy of $50 \mathrm{keV}$ for the $\mathrm{H}_{2}^{+}$test beam.

\section{A. Energy measurement}

We measured the beam energy of the RFQ using the time-of-flight (TOF) method. Figure 21 shows the distance between the FCT and BPM, and the corresponding time signals. The flight time of the beam over the distance of $180.0 \mathrm{~mm}$ is greater than double the rf period and less than triple the rf period. So, the flight time is equal to the sum of double the rf period and the time difference between the two signals. The error in the energy measurement can be calculated from the errors in the length and time measurements. The measurement tolerance of our timing system is $51.25 \mathrm{ps}$. According to the error transfer formula, the error in our energy measurement is $\pm 0.01 \mathrm{MeV}$. We made ten 

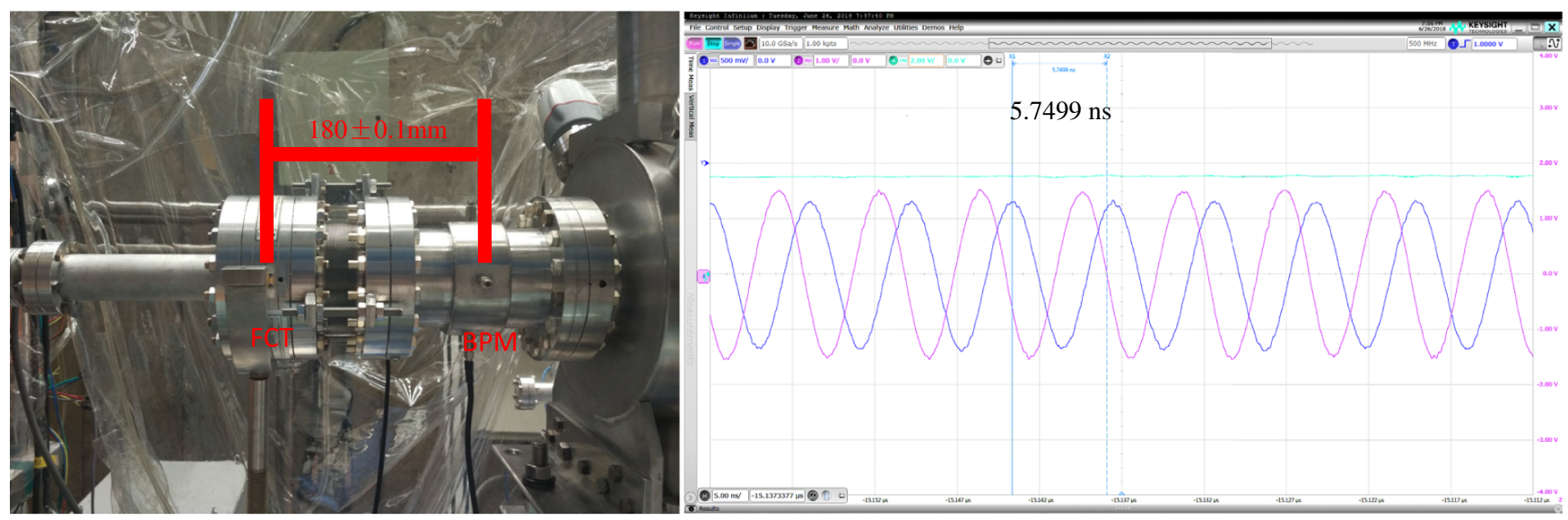

FIG. 21. Measured distance and beam signals detected by the FCT and BPM (the FCT signal is blue, the BPM signal is pink).
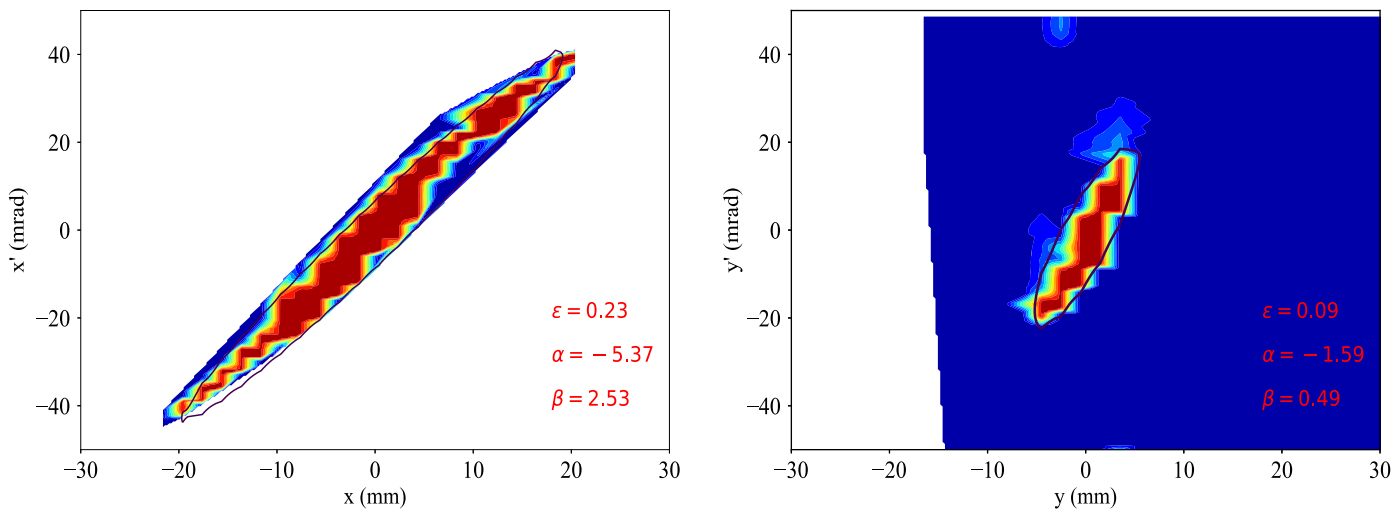

FIG. 22. Beam phase space at the measurement location.

measurements, and the averaged output energy of the RFQ is $1.04 \pm 0.01 \mathrm{MeV}$, which is consistent with the simulated value of $1.03 \mathrm{MeV}$.

\section{B. Beam transmission measurement}

We measured the beam emittance at the location of the first Faraday cup (FC1, see Fig. 20). Under the optimized parameters of the three solenoids, the measured phasespace distribution of the beam shows significant asymmetry in the $x$ and $y$ directions after the bending magnet, as shown in Fig. 22. Meanwhile, it can be noticed that the phase-space beam distribution also shows asymmetry in the $x$ direction. The asymmetry can be divided into two aspects, the displacement in the $x$ direction and the slight distortion of the beam. The former is caused by the collimation of the bending magnet, the latter is leaded by nonlinearities of the nonparaxial region of the solenoid 1 and solenoid 2. The Twiss parameters relative to the ellipse are used in transmission simulation. From the measurement location to the second Faraday cup (FC2, see Fig. 20), the simulated transmission efficiency, obtained using TraceWin code [18], is about $95 \%$ for a $1.5 \mathrm{~mA}$ beam. The measured transmission efficiency was $90.6 \% \pm 1.8 \%$ for a $1.5 \mathrm{~mA}$ pulsed beam. We suspected that part of the beam struck to the electrodes of the chopper because the current on the electrodes changed when beam passing by. Table V shows the comparison between the designed and measured Twiss parameters at the RFQ input and their

TABLE V. Comparison between the designed and measured Twiss parameters at the RFQ input and their corresponding transmission efficiencies.

\begin{tabular}{lcccc}
\hline \hline & $\alpha$ & $\beta[\mathrm{mm} / \mathrm{mrad}]$ & $\varepsilon_{\text {nor, } \mathrm{ms}}[\pi \mathrm{mm} \cdot \mathrm{mrad}]$ & Transmission $[\%]$ \\
\hline Design & 1.34 & 0.06 & 0.20 & 98 \\
Measured in $x$ direction & 1.21 & 0.09 & 0.22 & 95 \\
Measured in $y$ direction & 0.82 & 0.03 & 0.40 & \\
\hline \hline
\end{tabular}




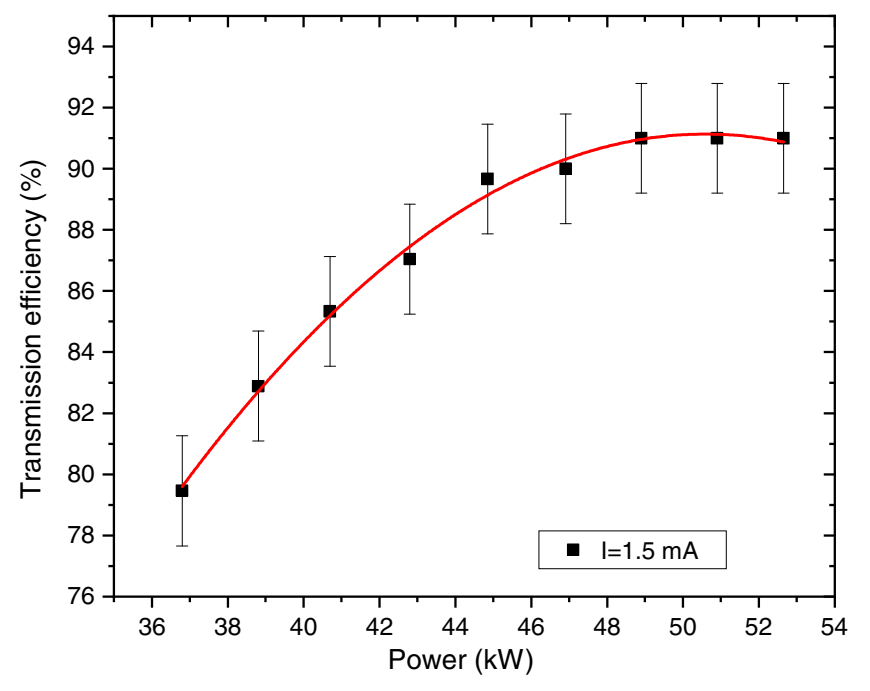

FIG. 23. Transmission efficiency as a function of RFQ cavity power.

corresponding transmission efficiencies. The measured one is actually deduced from the measured phase space shown in Fig. 22, using TraceWin code. It can be seen that the mismatch of the Twiss parameters can cause beam loss to some extent.

The experimental results for the pulsed-beam transmission under different RFQ cavity power are plotted in Fig. 23. The transmission efficiency remains almost constant for an input power greater than power of $49 \mathrm{~kW}$.

After obtaining these pulsed-beam results, we switched the RFQ into cw mode. Figure 24 shows the beam current at $\mathrm{FC} 1$ and $\mathrm{FC} 2$ during one hour of $\mathrm{cw}$ operation at a cavity power of $50 \mathrm{~kW}$. Due to sparks in the ECR ion source, the FC2 beam current drops off three times. Figure 25 shows the vacuum level of the LEBT, RFQ and beam dump during this one hour of cw operation. The RFQ vacuum is mostly stable at $8 \times 10^{-6} \mathrm{~Pa}$. The beam dump vacuum increased to

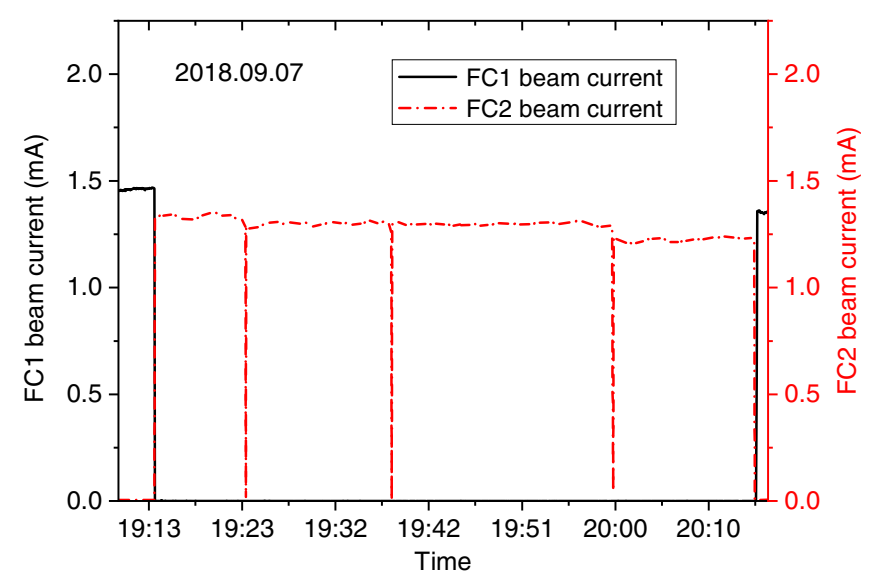

FIG. 24. Change of FC1 and FC2 beam current during one hour of cw operation.

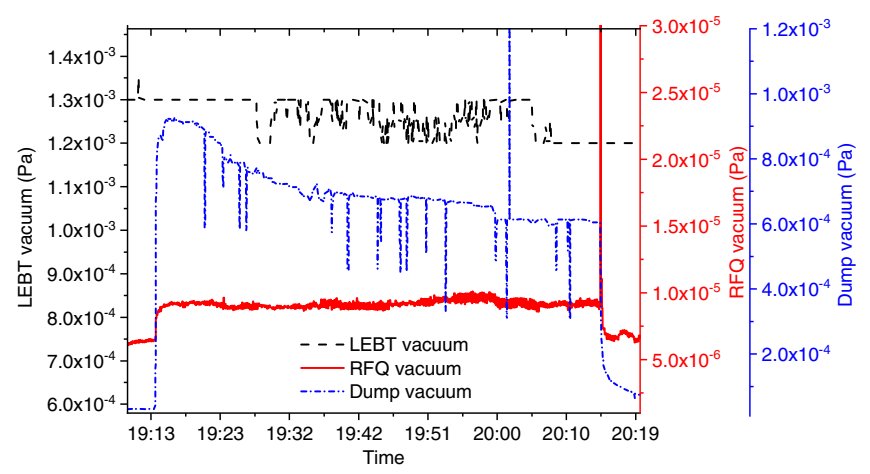

FIG. 25. Change of vacuum in LEBT, RFQ and beam dump during one hour of cw operation.

$1.25 \times 10^{-3} \mathrm{~Pa}$, then, gradually fell down. This is because there is an outgassing process when the beam bombards the Faraday cup. During cw running, the maximum temperature rise of the cooling water in $\mathrm{FC} 2$ is $3.6^{\circ} \mathrm{C}$, which is equivalent to absorbing power of $1.2 \mathrm{~kW}$, roughly consistent with the beam power. Additionally, the transmission efficiency of the cw beam does not vary much in the range from 1.5 to $2 \mathrm{~mA}$, with an average of over $90 \%$ transmission, as shown in Table VI.

\section{COMPARISION WITH OTHER DEUTERON RFQ}

There are currently five cw deuteron RFQs in the world. The main parameters of these RFQs are listed in Table VII. The SPIRAL2 RFQ, working at a low frequency of $88 \mathrm{MHz}$, is designed to accelerate heavy ions. Although it has demonstrated $1.34 \mathrm{~mA} \mathrm{He}{ }^{2+} \mathrm{cw}$ running with $98.5 \%$ transmission efficiency, it has not achieved its target performance levels $(\mathrm{cw}, 113.6 \mathrm{kV})$. The rest of these RFQs operate at higher frequencies. The SARAF phase I RFQ has achieved acceleration of a $1.15 \mathrm{~mA}$ deuteron beam in quasi-cw mode. However, the transmission is only around $70 \%$. The IFMIF RFQ and CMIF RFQ have completed beam commissioning in pulse mode, and are on their way to cw running. Our 973 RFQ is the first highfrequency window-type RFQ, and it has successfully accelerated a $1.78 \mathrm{~mA} \mathrm{H}_{2}^{+} \mathrm{cw}$ beam with $91.3 \% \pm 1.8 \%$ transmission efficiency.

TABLE VI. Transmission efficiency of cw beam under cavity power of $49.7 \mathrm{~kW}$.

\begin{tabular}{lcc}
\hline \hline $\begin{array}{l}\text { FC1 beam } \\
\text { current [mA] }\end{array}$ & $\begin{array}{c}\text { FC2 beam } \\
\text { current [mA] }\end{array}$ & Transmission [\%] \\
\hline 1.53 & 1.38 & 90.2 \\
1.65 & 1.48 & 89.7 \\
1.67 & 1.51 & 90.4 \\
1.95 & 1.78 & 91.3 \\
\hline \hline
\end{tabular}


TABLE VII. Main parameters of the deuteron cw RFQ in the world.

\begin{tabular}{|c|c|c|c|c|c|c|c|}
\hline Project & Type & $\begin{array}{l}\text { Frequency } \\
\quad(\mathrm{MHz})\end{array}$ & $\begin{array}{c}\text { Designed beam } \\
\text { current }(\mathrm{mA})\end{array}$ & $\begin{array}{c}\text { Intervane voltage } \\
\qquad(\mathrm{kV})\end{array}$ & $\begin{array}{c}\mathrm{E}_{\text {in }} / \mathrm{E}_{\text {out }} \\
(\mathrm{MeV})\end{array}$ & $\begin{array}{l}\text { Length } \\
\text { (m) }\end{array}$ & $\begin{array}{c}\text { Status and transmission } \\
\text { efficiency }\end{array}$ \\
\hline SPIRAL2 $[19,20]$ & 4 vane & 88 & 5 & 80 & $0.04 / 1.5$ & 5.08 & $\mathrm{cw} 1.34 \mathrm{~mA} \mathrm{He} \mathrm{He}^{2+} 98.5 \%$ \\
\hline SARAF [21] & $4 \mathrm{rod}$ & 176 & 5 & 56 & $0.04 / 3$ & 3.72 & $\mathrm{cw} 1.15 \mathrm{~mA} \mathrm{D}^{+} \sim 70 \%$ \\
\hline IFMIF $[22,23]$ & 4 vane & 175 & 130 & $79-132$ & $0.1 / 5$ & 9.78 & Pulse $13 \mathrm{~mA} \mathrm{H}^{+}$ \\
\hline CMIF [24] & 4 vane & 162.5 & 10 & 65 & $0.04 / 3$ & 5.26 & Pulse $8.04 \mathrm{~mA} \mathrm{H}_{2}^{+} 97.6 \%$ \\
\hline 973 RFQ & window & 162.5 & 50 & 60 & $0.05 / 1$ & 1.81 & $\mathrm{cw} 1.78 \mathrm{~mA} \mathrm{H}_{2}^{+} 91.3 \%$ \\
\hline
\end{tabular}

\section{SUMMARY}

We have constructed and tested the first high frequency window-type cw RFQ. The fabrication and assembly of the RFQ achieved high precision. For the low power test, the experimental and simulated results show good agreement. New coupling rules between quadrants are summarized and used to guide the field tuning. The rf conditioning results have indicated a successful rf structural design. For the beam commissioning, $\mathrm{H}_{2}^{+}$beam was accelerated to $1.04 \mathrm{MeV}$. The transmission efficiency from $\mathrm{FC} 1$ to $\mathrm{FC} 2$ is over $90 \%$ for $\mathrm{cw}$ beam of $1.5-2 \mathrm{~mA}$. Most recently, one hour of stable cw operation has been successfully demonstrated. These results illustrate the great success of this $\mathrm{cw}$ RFQ. The experience of the design and fabrication can be applied to future cw RFQs.

\section{ACKNOWLEDGMENTS}

Many thanks to the members of RFQ group at Institute of Modern Physics who have given lots of helps with the RFQ commissioning and many thanks also to the workers from Lanzhou Kejin Taiji Corporation., Ltd., who have made great contributions to the copper cavity fabrication. This work was supported by the National Basic Research Program of China (Grant No. 2014CB845503).

[1] J. Knaster, P. Cara, A. Kasughai, Y. Okumura, and M. Sugimoto, Challenges of the high current prototype accelerator of IFMIF/EVEDA, in Proceedings of the 7th International Particle Accelerator Conference, IPAC2016, Busan, Korea, 2016 (JACoW, Geneva, Switzerland, 2016), pp. 52-57, http://accelconf.web.cern.ch/AccelConf/ ipac2016/papers/mozb02.pdf.

[2] Z. L. Zhang, Y. He, A. M. Shi et al., Design of a four vane RFQ for China ADS project, in Proceedings of the 26th Linear Accelerator Conference (LINAC-2012), Tel-Aviv, Israel, 2012 (JACoW, Tel Aviv, 2012), pp. 942-944, http://epaper.kek.jp/LINAC2012/papers/ thpb039.pdf.

[3] P. Fischer, A. Schempp, and J. Hauser, A CW RFQ accelerator for deuterons, in Proceedings of the 21st Particle Accelerator Conference, Knoxville, TN, 2005 (IEEE, Piscataway, NJ, 2005), pp. 794-795, http://
accelconf.web.cern.ch/AccelConf/p05/PAPERS/RPAP002 .PDF.

[4] L. Young, Operations of the LEDA resonantly coupled RFQ, in Proceedings of the 19th Particle Accelerator Conference, Chicago, IL, 2001 (IEEE, New York, 2001), pp. 309-313, https://doi.org/10.1109/PAC.2001.987501.

[5] Y. He, High intensity RFQs: Review on recent developments, common problems, solutions, in Proceedings of the 8th International Particle Accelerator Conference, Copenhagen, Demark, 2017, http://accelconf.web.cern .ch/AccelConf/ipac2017/talks/wexa1_talk.pdf.

[6] F. J. Jia, K. Zhu, Y. R. Lu, Z. Wang, Z. Y. Guo, Q. Fu, and Y. He, Beam Dynamics Design of a $50 \mathrm{~mA} \mathrm{D+RFQ,} \mathrm{Chin.}$ Phys. Lett. 33, 072901 (2016).

[7] Q. Fu, K. Zhu, Y. R. Lu, M. J. Easton, S. L. Gao, Z. Wang, F. J. Jia, H. P. Li, P. P. Gan, and Y. He, Design and cold model experiment of a continuous-wave deuteron radio-frequency quadrupole, Phys. Rev. Accel. Beams 20, 120101 (2017).

[8] V. Andreev et al., First beam test of $81.25 \mathrm{MHz}$ RFQ for ITEP-TWAC, in Proceedings of the 2nd International Particle Accelerator Conference, San Sebastián, Spain, 2011 (IEEE, San Sebastián, Spain, 2011), pp. 2622-2624, http://accelconf.web.cern.ch/accelconf/IPAC2011/papers/ weps056.pdf.

[9] P. N. Ostroumov et al., Development and beam test of a continuous wave radio frequency quadrupole accelerator, Phys. Rev. ST Accel. Beams 15, 110101 (2012).

[10] A. Perry, C. Dickerson, P. Ostroumov, and G. Zinkann, Beam characterization of a new continuous wave radio frequency quadrupole accelerator, Nucl. Instrum. Methods Phys. Res., Sect. A 735, 163-168 (2014).

[11] V. Koshelev, Design of 4-vane RFQ with magnetic coupling windows for NUCLOTRON injector LU-20, in Proceedings of the 28th Linear Accelerator Conference, LINAC-2016 East-lansing, MI, 2016 (JACoW, Geneva, Switzerland, 2016), pp. 575-577, http://accelconf.web .cern.ch/AccelConf/linac2016/papers/tuplr050.pdf.

[12] CST, http://www.cst.com.

[13] R. Duperrier, TOUTATIS: A radio frequency quadrupole code, Phys. Rev. ST Accel. Beams 3, 124201 (2000).

[14] F. Naito, H. Tanaka, and K. Nanmo, Input coupler of the J-PARC DTL, in Proceedings of the 26th Linear Accelerator Conference (LINAC-2012), Tel-Aviv, Israel 2012 (JACoW, Tel Aviv, 2012), pp. 690-692, https://accelconf .web.cern.ch/AccelConf/LINAC2012/papers/tupb099.pdf.

[15] P. N. Ostroumov et al., High power test of a 57-MHz CW RFQ, in Proceedings of the 20th Linear Accelerator Conference (LINAC 2006), Knoxville, TN, 2006, 
THP079, pp. 767-769, http://epaper.kek.jp/106/PAPERS/ THP079.PDF.

[16] J. P. Duke et al., Measurements of rf cavity voltages by xray spectrum measurements, in Proceedings of International Linac Conference, Monterey, CA, 2000, MOC08, pp. 164-165, http://accelconf.web.cern.ch/ AccelConf/100/papers/MOC08.pdf.

[17] A. P. Zhukov, SNS RFQ voltage measurements using X-ray spectrometer, in Proceedings of IBIC 2016, Barcelona, Spain, 2016, pp. 154-165, http://accelconf.web.cern.ch/ AccelConf/ibic2016/papers/mopg44.pdf.

[18] D. Uriot and N. Pichoff, TraceWin, documentation, CEA/ DSM/DAPNIA/SEA/2000/4 (2000).

[19] R Ferdinand, Commissioning of SPIRAL2 cw RFQ and linac, in Proceedings of the 8th International Particle Accelerator Conference, Copenhagen, Demark, 2017, pp. 2462-2465, http://accelconf.web.cern.ch/AccelConf/ ipac2017/papers/weoaa1.pdf.

[20] R. Ferdinand, G. Congretel, A. Curtoni et al., SPIRAL2 RFQ design, in Proceedings of the 9th European Particle Accelerator Conference, Lucerne, 2004 (EPS-AG,
Lucerne, 2004), pp. 2026-2028, http://pdfs.semanticscholar .org/c8f9/6e236a323da2c567098928d4797d91dcbc43.pdf.

[21] L. Weissman et al., Installation, high-power conditioning and beam commissioning of the upgraded SARAF 4-rods RFQ, J. Instrum. 13, T05004 (2018).

[22] L. Bellan, M. Comunian, and E. Fagotti, Beam dynamics of the first beams for IFMIF-EVEDA RFQ commissioning, in Proceedings of the 9th International Particle Accelerator Conference IPAC2018, Vancouver, BC, Canada, http://accelconf.web.cern.ch/AccelConf/ipac2018/papers/ thpak019.pdf.

[23] E. Fagotti, L. Antoniazzi, L. Bellan et al., Beam commissioning of the IFMIF EVEDA very high power RFQ, in Proceedings of the 9th International Particle Accelerator Conference IPAC2018, Vancouver, BC, Canada, http:// accelconf.web.cern.ch/AccelConf/ipac2018/papers/ thxgbf2.pdf.

[24] W. P. Dou, W. L. Chen, F. F. Wang et al., Beam dynamics and commissioning of cw RFQ for a compact deuteronberyllium neutron source, Nucl. Instrum. Methods Phys. Res., Sect. A 903, 85 (2018). 